\title{
Lessons from the Implementation of MDGs in Kenya: Options for a Post-2015 Framework
}

\author{
Mwangi Waituru
}

\begin{abstract}
Kenya is playing a significant role in the development of post-2015 MDG and SDG frameworks. This is compatible with the desire of the new leadership to be more proactive in the negotiation of international agreements. However, the synergies between various leadership roles remain under-exploited, ultimately reducing Kenyan influence. In Kenya, the MDG period saw a fairly unsuccessful struggle to move away from the notion that the framework was an externally driven means to guide development assistance. While the present consultations around MDGs and SDGs might mean that governments will identify themselves more closely with the new framework, it does not mean that the framework will adequately reflect the views of the poor. Furthermore, there is a risk that a strong post-2015 framework will dilute the imperative of human rights. The human rights framework offers the prospect of more transformative change, and there is a risk that it will be undermined if it does not form the core of the post-2015 agreement.
\end{abstract}

As 2015 approaches, Kenya has a high-profile position in dialogue around the new development framework. Through Betty Maina (of the Kenya Association of Manufacturers), Kenya has provided one of the four African members of the High-Level Panel appointed by the SecretaryGeneral to advise on the global development framework beyond 2015, the target date for the Millennium Development Goals (MDGs). In the related dialogue on Sustainable Development Goals (SDGs), the Kenyan Permanent Representative to New York has been elected to co-chair the Open Working Group. A third Kenyan, the author of this piece Mwangi Waituru, is co-chairing the leading global campaign, Beyond 2015, which brings together over 700 civil society organisations and NGOs, seeking to influence the post-2015 framework.

However, the current leadership and influence that Kenyans are displaying in the post-2015 dialogue is not built on unwavering engagement or indisputable success during the MDG period. Indeed, this article presents an analysis of Kenya's response to the MDGs, highlighting ways in which the framework was seen as an external requirement guiding access to international aid, rather than a shared commitment to core development priorities. It provides lessons on how to build greater and more equitable ownership of global policy discourse.

\section{Implementing the MDGs}

Kenya's experience with the MDGs needs to be understood within the context of the economic, demographic and political trajectory of the country, both internally and with regard to international relations.

In the ten years prior to the MDG period, Kenya was struggling to provide basic services and support development. The effects of a freeze on bilateral aid, indebtedness and the strictures of structural adjustment had their roots in the 1980 s, resulting in deterioration at all levels, including widespread dilapidation of roads, power infrastructure, health care facilities, schools and government offices. A growing population demanded improved services, and the government had struggled to meet its obligations.

In this context, the government was highly likely to agree to any international development framework that brought with it the promise of 
development assistance. The MDGs, which appeared to be an agreement between donor and recipient countries (Melamed 2011), were thus timely and welcome.

Having signed up to the MDGs, however, the government response reflected the notion that the framework was essentially top-down, with work towards the goals very much the agenda of the donors. The MDG process had no traction until 2004, when work started on preparations for the MDGs +5 summit. With financial motivation from the Government of Finland and the United Nations Development Programme (UNDP), the Government of Kenya agreed to implement 'Mainstreaming MDGs in Kenya's Development Process' (known as the MDGs Project, with an implementation unit established under the Ministry of Finance). Its objective was to mainstream MDGs in the planning, budgetary and development processes.

Under this project, one of the first actions taken by the government was a cost study that sought to establish a budget for achieving the MDGs. The study identified a financing gap of KSh 4.1 trillion (Mailu 2013), some four times larger than the annual national budget. The study further underpinned the notion that the MDGs were an external framework, far removed from the possible business of government.

In time, however, the MDGs Project managed to develop a level of influence across government (Muyumbu 2008). A cabinet directive in 2005 required all ministries to mainstream MDGs in their policies, programmes, budgets and operations. This brought the MDGs into a more central position in the country's development process. By 2009, sectoral planning units had been trained on MDG mainstreaming, and government required each ministry to ensure that at least two MDGs or core poverty-related projects were explicitly reflected in their programmes, targets and reporting.

Despite apparently greater traction, however, progress towards the achievement of MDGs remained slow. In line with many other countries, the MDGs Project in Kenya signed up to a project promoted by UNDP. Nine pilot districts were selected as sites for the development of best practices for MDG achievement, intended for national scale-up. While results in those districts may have been positively impacted by the project, it is nonetheless clear that the generic and project-based response to slow progress was strongly indicative of a process that had remained strongly donor-driven, and outside the core business of government.

Further, a lack of coherence between the MDGs and other instruments for development planning creates cause for concern. For example, the Vision 2030 process, driven in many countries by the World Bank, has subsumed the aim of reducing poverty under targets for economic growth. The diversity of somewhat ambiguous frameworks and targets serves to reinforce the idea that they are essentially a means for directing external assistance.

\section{Towards the new development framework}

As we move towards 2015, a lot has changed in Kenya that is likely to influence engagement in both design and implementation.

The newly elected government is led by a President and Deputy President who are facing charges at the International Criminal Court (ICG), emanating from the post-election violence of 2008. This is so because Kenya is a signatory to the treaty that establishes the ICC; most likely given in the spirit of hoping and/or believing that this and similar assents were a requirement for development assistance.

One consequence of this that is already very clear is that the government will be more proactive in the design of international agreements, and more careful in deciding what it chooses to endorse.

The current Kenyan leadership will undoubtedly develop a strong position on post-2015 proposals. Furthermore, it is likely to work to mobilise peer support for this position from the African Union (AU), and to help strengthen the voice of the AU in global debates.

Despite being represented in both, Kenya's influence on the interplay and outcome of having parallel MDG and SDG processes could be greatly strengthened. Given the different origins and separate paths of each, the work around both at national level has remained rather separate. It is hosted under different ministries (Planning and Environment respectively), without any active process of coordination or collaboration. Further, Kenya's engagement at 
global level as co-chair of the SDG Open

Working Group is a third separate process. The Permanent Representative's work has been conducted with no reference to the domestic processes around MDGs and SDGs, and with no links to the lead ministries. Despite the Kenyan government's wish to increase its engagement in international processes, this splintered and uncoordinated approach has greatly diluted the potential influence that Kenya could have on the outcomes of the post-2015 MDG/SDG debate.

The sense that the MDGs and any possible successors are externally driven and top down remains strong in Kenya. A recent consultative meeting on post-2015 saw one senior government officer asking why the government should pursue distractive global frameworks when it had a national development agenda to pursue. Some complained that the donors had not produced funds to support 'their' MDGs, whilst others argued that Kenya had spent too much on reporting, monitoring and evaluation that had been required elsewhere.

Given such feelings, it is unlikely that the Kenyan government will endorse a global framework that appears limited to guiding aid deliveries. In contrast, an acceptable new framework for the country is likely to be economic growth-oriented, setting out commitments of all nations to fairer and more equitable development. This agenda may encompass fairer terms of trade, climate change, tax justice, representative global governance and so on.

\section{A policy framework for the people}

Notwithstanding the significance of national and international processes, it is important to remember that the post-2015 framework is not for states, but for people. Outside government, the people of Kenya are asking how the new framework will influence the policies that affect their daily lives. They want to know how it will contribute to the realisation of rights and to providing human dignity to Kenyans.

There are many examples of processes and movements, at the national and local level, seeking concrete changes for ordinary Kenyans. The civil society organisations engaged in these struggles see these as a necessary means of addressing structural inequalities, intended to bring about a transformative shift in power and resource distribution. In this context, there are pertinent questions about the effectiveness of a global framework. In particular, there are fundamental concerns around whether national governments and multinational organisations are likely to agree to and give leadership around the sort of structural changes that are needed to address inequalities at all levels.

There are times when the policies and programmes adopted in pursuit of these have been grounded in a 'charitable' approach. At best, this has failed to address the root causes of poverty or expand the realisation of human rights. At worst, it can smother the pursuit of transformative change and perpetuate vulnerability and dependence. Where 'development' comes to mean rather lacklustre progress on some basic needs, it cannot be said to reflect a framework or agenda that seeks genuine change for the poor.

If the results of the new development agenda are to achieve transformative change for the majority of Kenyans, it is important that the MDG/SDG frameworks are grounded in human rights and reinforce existing state commitments to international human rights commitments. There is a risk that MDG/SDG frameworks will fall short of the standards and goals already framed in international treaties, thus providing a convenient distraction, and a basis on which states can fall short of the human rights standards already agreed.

In 2010, the Seed Institute and the African Monitor conducted a series of poverty hearings in Kenya, Liberia, Mozambique and South Africa. A panel of eminent persons listened to first-hand testimonials from people living in poverty - testimonials that were given with great dignity. It was notable that the people who spoke were not waiting for charity, but seeking opportunity to improve their lives. Some were forced into impossible and risky choices but they were fighting for their lives. A case in point was an HIV-positive 14-year-old Kenyan boy who proudly narrated how he had built for himself a house from profits made out of selling diesel fuel syphoned by truck drivers from the trucks they are employed to drive (Seed Institute 2010).

From the poverty hearings, it is clear that people are sure about the development they want to see. 
As grassroots communities describe their lived realities, it is evident that what they envision is not necessarily what outsiders think they want. The strongest message from communities is a deep desire for the power to make decisions on issues that affect their lives; for access to equal opportunities; and for an enabling environment to sustain livelihoods.

Brought to bear on the Post-2015 Development Agenda, this evidence means that whatever framework is agreed upon, it must help the poor of Kenya and other African countries to meet these goals. The power to make decisions that affect their lives requires greater emphasis on building democratic governance and accountability; access to equal opportunities depends on addressing inequalities and exclusions across class, gender, religion, clan and other grounds of discrimination; an enabling environment to sustain their livelihoods depends on inclusive and pro-poor economic development, underpinned by secure access to supportive and high-quality services.

In talking about the future they want, people presented a catalogue of experience ranging from chronic vulnerability through narratives of exclusion, discrimination, corruption, insecurity and crime, inadequate skills and lack of opportunities to own assets. Unlocking the African moment requires removal of these hindrances. It is important to note that this depends on a composite 'package'. Improvements in any particular domain will be greatly undermined by failures in others.

\section{Concluding remarks}

This analysis suggests that Kenya cannot be said to have achieved any MDG goals and targets as a

\section{References}

Mailu, G. M. (2013) Kenya's MDGs Status to Date, http://www.finland.or.ke/public/download.aspx ?ID $=110265 \&$ GUID = \%7B8AF512AF-BBB44ADA-AE0B-19BFDD4AF4C3\%7D (accessed 17 June 2013)

Melamed, C. (2011) The Millennium Development Goals After 2015: No Goals Yet Please, London: ODI, result of the MDG process, as such. There has certainly been some progress in some of these areas, and this has to an extent been influenced or driven by the MDG framework. However, the sense that the MDG process was an externally driven process intended to precipitate aid flows has in many ways marginalised and perhaps confused the process of expanding national ownership for basic development outcomes.

In the current context in Kenya, the country is well positioned to influence the Post-2015 Development Agenda through the MDG and SDG processes. However, a more strategic approach amongst those institutions and individuals involved is required for this opportunity to yield the desired results. Given the particular issues that affect the new Kenyan leadership, and its desire to influence the international process, it is hoped that the necessary improvements can be realised.

A bigger question, however, is whether a development framework is likely to precipitate transformative change. International human rights treaties establish standards that provide for human dignity, equality and opportunity, but the lives of the poor fall far short of almost every provision. There is a risk that a development framework will dilute the imperative of the human rights framework, focusing instead on a more limited selection of symptoms of poverty and rights failures. In so doing, it would not support the aspirations of the poor, and indeed might reduce prospects for transformative change. Ensuring that the post-2015 development framework is sufficiently ambitious, and takes a rights-based approach, remains a critical challenge.

www.odi.org.uk/opinion/details.asp?id $=5981 \&$ title $=$ mdgs-millennium-development-goalspost-2015-goals-targets (accessed 20 June 2013) Muyumbu, G. (2008) What Space for Civil Society Organizations in MDGs?, Nairobi: Global Campaign Against Poverty, Kenya Seed Institute (2010) Report of the Kenya National Poverty Hearing, Nairobi: Seed Institute 